\title{
Recent advances in paediatric respiratory medicine
}

\author{
Andrew Turnbull, lan M Balfour-Lynn
}

Department of Paediatric Respiratory Medicine, Royal Brompton Hospital, London, UK

\section{Correspondence to} Dr Ian M Balfour-Lynn, Department of Paediatric Respiratory Medicine, Royal Brompton Hospital, Sydney Street, London SW3 6NP, UK; i.balfourlynn@ic.ac.uk

Received 4 May 2015 Revised 22 July 2015 Accepted 28 July 2015 Published Online First 19 August 2015

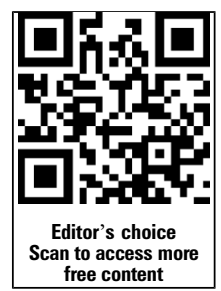

CrossMark

To cite: Turnbull A, BalfourLynn IM. Arch Dis Child 2016;101:193-197.

\begin{abstract}
This review highlights important advances in paediatric respiratory medicine since 2014, excluding cystic fibrosis. It focuses mainly on the more common conditions, bronchopulmonary dysplasia, bronchiolitis and preschool wheezing, asthma, pneumonia and sleep, and highlights some of the rarer conditions such as primary ciliary dyskinesia and interstitial lung disease (ILD).
\end{abstract}

In recent years, the most exciting advances in paediatric respiratory medicine have been the use of small molecule therapy in people with cystic fibrosis with specific gene mutations; this has been covered in a recent review by Davies et al. ${ }^{1}$ In this article, we have highlighted the most important advances in respiratory paediatrics from 2014 onwards, outside of cystic fibrosis.

\section{RESPIRATORY SEQUELAE OF PRETERM BIRTH AND BRONCHOPULMONARY DYSPLASIA}

Bronchopulmonary dysplasia (BPD), as defined by persistent dependence on supplementary oxygen at 28 days of life or 36 weeks gestational age in preterm infants, has a well-described association with respiratory symptoms in childhood and adolescence. $^{2}$ Advances in neonatal care since the 1990s, including the use of artificial surfactant and more sophisticated modes of respiratory support, have significantly improved survival of extremely preterm infants, although at the cost of long-term respiratory morbidity. The EPICure cohort, born in 1995 and followed up at 11 years, showed a higher prevalence of respiratory symptoms, airways obstruction and bronchodilator responsiveness in children born extremely preterm compared with controls, with the greatest morbidity in those infants who had BPD. ${ }^{3}$ A recent study compared 28 infants born at 24-33 weeks gestation with BPD, with 28 matched preterm infants without $\mathrm{BPD}$, finding increased symptoms and reduced lung function in the BPD group at 9.5 years. ${ }^{4}$ In a cohort study in which ex-preterm infants with and without BPD, as well as healthy infants born at term, were followed into their mid-20s, Gough et $a l^{5}$ found an increase in reported respiratory symptoms and physician-diagnosed asthma in the BPD group compared with full-term controls, but not compared with the ex-preterm non-BPD group. Forced expiratory volume in $1 \mathrm{~s}$ and mid-expiratory flows were significantly lower in the BPD group compared with full-term controls and non-BPD preterm infants. Interestingly, a significant proportion of preterm infants without BPD in both of these studies still had airflow obstruction and bronchodilator reversibility on spirometry, despite not reporting symptoms. Collectively, the evidence suggests that while survivors of BPD have increased symptoms and impaired lung function in later childhood and young adulthood, subclinical lung function abnormalities also exist in a proportion of those without BPD. The functional consequences of these may be important once they reach later adulthood, but this is not yet clear.

\section{NEBULISED HYPERTONIC SALINE FOR BRONCHIOLITIS}

Bronchiolitis continues to be a cause of significant morbidity and healthcare resource use worldwide. A Cochrane systematic review concluded that nebulised 3\% hypertonic saline (HS) may significantly shorten length of stay in infants hospitalised with acute bronchiolitis, ${ }^{6}$ although the studies were mostly small and heterogeneous in design. Subsequent trials have continued the debate. In an emergency department setting, Florin et $a l^{7}$ showed no benefit in 31 children following a single dose of nebulised 3\% HS compared with nebulised ('normal') $0.9 \%$ saline in the respiratory distress score at $1-2 \mathrm{~h}$, or in secondary outcomes including rate of hospitalisation. However, a larger study in 408 children $<2$ years compared multiple doses of $3 \%$ HS vs $0.9 \%$ saline commenced in the emergency department and continued throughout admission. ${ }^{8}$ A reduction in admission rates was seen in the HS group, without an effect on respiratory distress scores. ${ }^{8}$ In both groups, albuterol (salbutamol) was administered prior to the study drug.

In a double-blind, randomised controlled trial (RCT) of 290 children aged 0-24 months admitted to hospital with a diagnosis of bronchiolitis, treatment with nebulised 3\% HS or nebulised 6\% HS was compared with nebulised $0.9 \%$ saline given every $8 \mathrm{~h}$ for the duration of admission. ${ }^{9}$ All study drug doses were given along with $2.5 \mathrm{mg}$ nebulised salbutamol. The primary outcome of length of hospital stay was not significantly different between the study groups, nor was there any significant difference in the need for supplemental oxygen, tube feeding or clinical severity scores. As with previous studies, the use of nebulised $0.9 \%$ saline as a control is controversial, as it is not standard treatment for bronchiolitis and it may not be without effect. This difficulty was overcome by the Hypertonic Saline in Acute Bronchiolitis RCT and Economic Evaluation trial, which randomised infants hospitalised with acute bronchiolitis to receive either 3\% HS (given every $6 \mathrm{~h}$ for the duration of admission) or standard care. ${ }^{10}$ In the 290 patients included in the analysis, there was no difference in the primary outcome of time to be declared fit for discharge, or the secondary outcomes of time to actual discharge or incidence of adverse events. Despite the risk of potential bias, the open design of the study enabled the active intervention (nebulised 3\% HS) to be compared 
with true standard care (no nebulised therapy), thus adding further to the evidence of lack of benefit of using HS in this condition. The search for useful therapies continues.

\section{NATIONAL REVIEW OF ASTHMA DEATHS}

The National Review of Asthma Deaths ${ }^{11}$ is critical reading. It highlights essential lessons for all those involved in the care of children and adults with asthma, and reminds us that getting the basics right is still the cornerstone of good care. This confidential enquiry reviewed 195 deaths in the UK attributed to asthma during the year from February 2012, and identified potentially avoidable factors in over two-thirds of deaths. These included under-recognition of asthma severity, failure to recognise poor control (exemplified by excessive prescription of reliever inhalers), inadequate prescription of preventive inhalers, inadequate follow-up following an acute attack and poor provision of chronic asthma services and education. Lack of appropriate primary and specialist care was significant, with $43 \%$ of those who died having no evidence of an asthma review in general practice in the year before death, and 57\% not registered as under specialist care in the year prior to death. Provision of a personal asthma action plan was documented in only $23 \%$ of those who died. The recommendations from this report are comprehensive, outlining the need for structured clinical reviews to assess asthma control, identify precipitating factors and provide education and personalised asthma action plans, as well as the need for electronic prescription surveillance and national audit. Greater integration between primary and specialist services is emphasised, with clear lines of responsibility and pathways of referral, along with attention to guideline-based care. At every patient encounter, the need for vigilant monitoring and proactive preventative care is clear.

\section{ASTHMA: UPDATED BTS/SIGN GUIDELINES (2014)}

The 2014 revision of the British Guideline on the management of asthma maintains many of the key recommendations of the 2011 version, with some important updates where new evidence is available. ${ }^{12}$ Significant revisions are made to the organisation and delivery of services with emphasis on the need to prioritise and support self-management. Key recommendations are made that relate to the 11 specific quality statements made in the National Institute for Health and Care Excellence 2013 quality standard for asthma. The full updated BTS/SIGN guideline can be found at https:// www.brit-thoracic.org.uk/document-library/clinical-information/ asthma/btssign-guideline-on-the-management-of-asthma/

\section{IMPACT OF BACTERIA ON ASTHMA DEVELOPMENT AND EXACERBATIONS}

Following evidence from the Copenhagen Prospective Study on Asthma in Childhood indicating a link between neonatal bacterial airway colonisation and later asthma risk, ${ }^{13}$ Larsen et al ${ }^{14}$ suggested that an abnormal response to airway bacterial colonisation in infancy is associated with later development of asthma. In their analysis of cytokine levels and T-cell activation patterns in stimulated peripheral blood mononuclear cells from 292 infants at 6 months of age, they found significantly elevated levels of interleukin (IL)-5, IL-17 and IL-10 production in cells from infants who later developed asthma, compared with those who did not. No difference was seen in T-cell activation or peripheral T-cell composition. They suggest this altered response to airway bacteria in early life may permit persistent colonisation and predispose to the chronic inflammation of asthma. Testing this hypothesis in other birth cohorts may give interesting insights into early origins of asthma pathogenesis.
The impact of bacterial isolation and bacterial/viral co-infection on asthma exacerbations has been studied by Kloepfer et al. ${ }^{15}$ Using molecular detection methods, they analysed weekly nasal swabs from 308 children with and without asthma during the peak rhinovirus season. A positive rhinovirus PCR increased the likelihood of bacterial isolation, either concurrently or the following week, but bacterial isolation did not increase the likelihood of subsequent viral isolation. Bacterial isolation rates were equal between asthmatics and nonasthmatics. Isolation of either rhinovirus or Streptococcus pneumoniae was associated with moderate asthma exacerbations, which were greater when these two pathogens were isolated together. Co-infection with rhinovirus and either S. pneumonia or Moraxella catarrhalis, but not Haemophilus influenza, increased cold and asthma symptoms. These findings contribute important information into the heterogeneity of asthma exacerbations during the rhinovirus season, and prompt further investigation into the role of pathogenic bacteria.

\section{THE EFFECT OF ELECTRONIC MONITORING/REMINDER DEVICES ON ASTHMA ADHERENCE AND CONTROL}

Poor adherence to maintenance asthma therapies is well described, ${ }^{16}$ and has been shown to be associated with reduced asthma control. ${ }^{18-21}$ Electronic devices to monitor and promote adherence have recently become available and are being tested in clinical practice. ${ }^{22} 23$ In a recent study by Chan et al, ${ }^{24} 220$ young people aged 6-15 years with asthma, and on inhaled corticosteroids (ICS), were randomised to receive an electronic monitoring device with an audiovisual reminder function, either enabled (intervention group) or disabled (control group). Follow-up was every 2 months for 6 months, with the primary outcomes being adherence to ICS and number of school-absentee days (for any reason). A marked difference was observed in the median adherence between the intervention group (84\%) and the control group (30\%), although surprisingly no significant difference was seen in the proportion of days absent from school $(1.9 \%$ vs $1.7 \%)$. There were, however, significantly greater improvements from baseline in asthma morbidity scores in the intervention group compared with the control group, and a significantly lower percentage of days where a reliever inhaler was used in the intervention compared with control group. No significant differences were seen in lung function or emergency department visits, however. As has been shown previously, ${ }^{17}$ adherence fell in both groups over time, but no difference was seen in the rate of decline between groups. The findings of this study add to the evidence that electronic reminder devices can improve adherence (especially in young people in whom forgetfulness is a common cause of poor adherence $^{23}$ ), and importantly, can have an impact on some but not all measures of asthma control. Whether that impact is sufficient, and can be sustained, is not yet clear. The additional utility of electronic monitoring devices to help differentiate poor response to therapy from poor adherence contributes to the case for integrating this technology into selected clinical settings.

\section{INTERMITTENT MONTELUKAST FOR PRESCHOOL WHEEZE}

The evidence to support the use of montelukast as an intermittent therapy for preschool wheeze is conflicting. One previous RCT showed a modest reduction in unscheduled healthcare resource usage in preschool children treated with montelukast at the onset of each upper respiratory tract infection or asthma symptoms, ${ }^{25}$ whereas other trials of similar design have shown no significant benefit. ${ }^{26} 27$ Further evidence has been added by a 
recent large RCT of 1358 preschool children with a history of previous wheezing episodes, the Wheeze And Intermittent Treatment trial. ${ }^{28}$ Intermittent montelukast was commenced at the start of each viral cold or wheezing episode. The investigators found no significant difference in the primary outcome of unscheduled medical attendances for wheezing episodes, or in many of the secondary outcomes (number or duration of wheeze episodes, time to first medical attendance). Based on previous observations that response to montelukast varies depending on polymorphisms in the promoter region of the arachidonate 5-lipoxygenase (ALOX5) gene, the authors prospectively allocated patients into each study arm dependent on ALOX5 promoter genotype. Patients homozygous for the major ALOX5 promoter allele (denoted 5/5) had a reduction in unscheduled medical attendances with intermittent montelukast therapy compared with placebo, but this was not seen in the other ALOX5 promoter gene classifications (5/x and $\mathrm{xx}$, where $\mathrm{x}$ represents any number other than 5). This finding suggests that response to montelukast in children with preschool wheeze is heterogeneous, and hence a therapeutic trial may still be warranted in this group: this is a more pragmatic approach than genotyping all wheezing children.

\section{CHANGING EPIDEMIOLOGY OF CHILDHOOD PNEUMONIA AND EMPYEMA}

The incidence of empyema in UK children increased significantly during the late 1990s and early 2000s, along with an increase in the incidence of pneumonia in preschool children. ${ }^{29}{ }^{30}$ As $S$. pneumoniae is the most common pathogen to cause pneumonia and empyema in children, ${ }^{31} 32$ the impact of the pneumococcal conjugate vaccine (PCV) on the epidemiology of these conditions is of particular importance. The 7 -valent vaccine, PCV7 (containing protein from serotypes 4, 6B, 9V, 14, $18 \mathrm{C}, 19 \mathrm{~F}$ and $23 \mathrm{~F}$ ), was introduced into the UK immunisation schedule in September 2006, and was subsequently replaced by the 13-valent PCV13 (with the additional serotypes 1, 3, 5, 6A, $7 \mathrm{~F}$ and 19A) in April 2010. Nath $e a^{33}$ report on the incidence of paediatric empyema in Scotland, finding that total empyema admissions increased from the pre-PCV7 era to the 3-year period after PCV7 introduction (driven by an increase in children aged 1-9 years) before falling in the 3-year period after introduction of PCV13. Empyema rates in 2013 were still significantly higher than in 2000. Rates of pneumonia also increased after introduction of PCV7 (although only in children aged 5-14 years) and fell after PCV13, with no overall change between 2006 and 2013. Of the empyema cases after 2006 in which pneumococcal serotype data were available $(<20 \%)$, all were caused by serotypes not included in PCV7.

Data from other European and American studies have shown reductions in pneumonia incidence shortly after the introduction of PCV7, with the effect seen in vaccinated children ${ }^{34-36}$ and older children and adults due to herd immunity. ${ }^{30} 37$ Other studies on empyema incidence show mixed results, with a reported decline after PCV7 in England and Wales, ${ }^{30}$ and an observed increase in the USA. ${ }^{36}$ Data from the Health Protection Agency show a substantial decline in invasive pneumococcal disease following PCV7 introduction, with a marked decline in disease due to PCV7 serotypes but a relative increase in non-PCV7 serotypes. ${ }^{38}$ This phenomenon of serotype replacement has been observed in other studies, in which predominantly non-PCV7 serotypes have been identified in empyema cases in the post-PCV7 era, particularly serotypes 1, 3, 19A and 7A/F. ${ }^{39} 40$ Serotypes $19 \mathrm{~A}$ and 3 have previously been reported in association with more severe disease and a greater frequency of bronchopleural fistula, respectively. ${ }^{41} 42$ Replacement of PCV7 serotypes with non-PCV7 serotypes of different pathogenicity is therefore a possible cause of the observed increase in empyema incidence seen in the post-PCV7 era. Early data suggest that pneumonia and empyema incidence is declining since the introduction of PCV13, ${ }^{33}$ although longer term studies will be needed to determine if serotype replacement again occurs. Further research is still needed to determine which factors, if any, predict risk of empyema development in children with pneumonia.

\section{ADENOTONSILLECTOMY FOR OBSTRUCTIVE SLEEP APNOEA}

Obstructive sleep apnoea syndrome (OSAS) is estimated to affect $2 \%-5 \%$ of children, and adenotonsillectomy is the principle treatment. ${ }^{43}{ }^{44}$ The Childhood Adenotonsillectomy Trial (CHAT) compared early adenotonsillectomy against 'watchful waiting and supportive care' in 464 children aged 5-9 years with OSAS confirmed on polysomnography (PSG). ${ }^{45}$ Children with severe OSAS (defined by an obstructive apnoea-hypopnoea index of $>30$ events per hour; an obstructive apnoea index $>20$ events per hour; or oxyhaemoglobin saturation $<90 \%$ for $\geq 2 \%$ of total sleep time) were excluded. The primary outcome was change in attention and executive function determined by neuropsychological testing, and no significant difference was observed between the two regimens. Greater improvements were seen in a number of secondary outcomes, however, including symptoms, PSG scores, behaviour and quality of life, in the adenotonsillectomy group. Importantly, although a greater proportion of children in the adenotonsillectomy group had normalisation of their PSG scores, there was still normalisation of PSG scores in $46 \%$ of those in the watchful-waiting group. However, only $15 \%$ in this group achieved complete resolution of symptoms.

Chervin et $a l^{46}$ further explored the characteristics of the watchful waiting group to examine features that predicted resolution of PSG changes and symptoms. The only independent predictors of PSG resolution were mild OSAS and absence of central obesity. Symptom resolution was similarly predicted by milder symptoms at baseline, underlining the message that medical management alone may be appropriate for many children with mild symptoms and a mild PSG score, an approach more in keeping with current UK practice.

Of the 221 children in the CHAT study who underwent adenotonsillectomy, the rate of postoperative complications (early and late) was relatively low at $7 \%$, with the most common being dehydration and haemorrhage. ${ }^{47}$ In this population of schoolaged children with mild OSAS and without significant comorbidities, neither demographic factors nor PSG scores were predictive of complications. $^{47}$

\section{ADVANCES IN DIAGNOSTICS AND PHENOTYPING OF PRIMARY CILIARY DYSKINESIA}

Primary ciliary dyskinesia (PCD) is a rare, usually autosomalrecessive inherited disorder of motile cilia, which manifests as chronic suppurative lung disease, rhinosinusitis, hearing impairment and defects in organ laterality in approximately $50 \%$ of cases. ${ }^{48-50}$ Diagnosis relies on clinical history, nasal nitric oxide, analysis of ciliary beat pattern and frequency by light microscopy and ultrastructural analysis by transmission electron microscopy (EM). The expanding knowledge of PCD-associated gene mutations is furthering diagnostic capabilities, particularly in up to $30 \%$ where ciliary ultrastructure is unhelpfully normal on EM. ${ }^{49}$ To date, over 30 disease-associated mutations have 
been identified, which encode proteins involved in ciliary synthesis, structure and function, and which are estimated to account for $60 \%-65 \%$ of known cases of PCD. ${ }^{49}{ }^{51}$ The pace of discovery of PCD-associated mutations is rapid, with biallelic loss-of-function mutations in the RSPH1 gene being recently discovered and linked with a milder disease phenotype than 'classic' PCD..$^{52}$

In a prospective study of the phenotypic features associated with different ultrastructural and genetic defects in 118 paediatric patients with $\mathrm{PCD}$, Davis $e t a l^{53}$ identified neonatal respiratory distress (82\%), chronic cough $(99 \%)$ and chronic nasal congestion (97\%) as the prominent clinical features. Analysis by genotype and ultrastructural defect revealed significant heterogeneity in lung disease, although particular mutations (CCDC39 and CCDC40 linked with internal dynein arm defects and central apparatus defects with microtubular disorganisation, respectively) were associated with more severe disease. ${ }^{53}$ The recent advances in PCD diagnostics and the collaborative efforts to characterise genotype-phenotype correlations should enhance the evidence base from which improvements in management and outcomes can be achieved.

\section{CHILDHOOD ILD}

Childhood ILD describes a diverse group of rare diseases in which there is remodelling of the interstitium and distal airspaces, resulting in abnormal gas exchange and diffuse radiographic infiltrates. ${ }^{54} 55$ As the disease process may not be confined to the interstitium, the term 'diffuse lung disease' is proposed, ${ }^{5456}$ which, after the exclusion of more common disorders such as recurrent infection, BPD, cystic fibrosis, aspiration lung disease, immunodeficiency states, PCD and congenital cardiac disease, incorporates a spectrum of rare disease entities largely distinct from adult patterns of ILD. A multicentre review of 187 children under 2 years with diffuse lung disease identified a diverse group of disorders, which could be broadly classified according to clinical, genetic and histopathological features. ${ }^{56}$ Known genetic causes of ILD include mutations in the surfactant protein genes $(\mathrm{SpB}$ and $\mathrm{SpC})$ as well as mutations in the ATP-binding cassette transporter A3 (ABCA3), involved in posttranscriptional surfactant processing, and thyroid transcription factor 1 (TTF1), a transcription factor for $\mathrm{SpB}, \mathrm{SpC}$ and TTF1. Genotype-phenotype correlations in ABCA3 mutations have been recently described by Wambach et al. ${ }^{57}$

An American Thoracic Society clinical guideline on the classification, evaluation and management of childhood ILD in infancy was published in $2013 .{ }^{54}$ Due to the rarity and diversity of paediatric ILD there is a lack of standardisation in diagnostic and management approaches, and importantly, no RCTs of treatment. International collaborations, the Children's Interstitial and Diffuse Lung Disease Research Network in the USA and the European Management Platform for Childhood Interstitial Lung Disease (chILD-EU) project aim to overcome these challenges through standardising evaluation and treatment approaches, collection of clinical data in a centralised database and use of a tissue biobank to enable studies into disease pathogenesis. ${ }^{58}$ Through these ambitious collaborations between clinicians, scientists and patients groups, the ultimate aim of conducting an RCT of treatment in ILD will hopefully be realised.

\section{Competing interests None declared.}

Provenance and peer review Commissioned; externally peer reviewed.

\section{REFERENCES}

1 Davies JC, Ebdon AM, Orchard C. Recent advances in the management of cystic fibrosis. Arch Dis Child 2014;99:1033-6.

2 Doyle LW, Faber B, Callanan C, et al. Bronchopulmonary dysplasia in very low birth weight subjects and lung function in late adolescence. Pediatrics 2006;118:108-13.

3 Fawke J, Lum S, Kirkby J, et al. Lung function and respiratory symptoms at 11 years in children born extremely preterm: the EPICure study. Am J Respir Crit Care Med 2010;182:237-45.

4 Vom Hove M, Prenzel F, Uhlig HH, et al. Pulmonary outcome in former preterm, very low birth weight children with bronchopulmonary dysplasia: a case-control follow-up at school age. J Pediatr 2014;164:40-5.e4.

5 Gough A, Linden M, Spence $D$, et al. Impaired lung function and health status in adult survivors of bronchopulmonary dysplasia. Eur Respir J 2014;43:808-16.

6 Zhang L, Mendoza-Sassi RA, Wainwright C, et al. Nebulised hypertonic saline solution for acute bronchiolitis in infants. Cochrane Database Syst Rev 2013;7: Cd006458.

7 Florin TA, Shaw KN, Kittick M, et al. Nebulized hypertonic saline for bronchiolitis in the emergency department: a randomized clinical trial. JAMA Pediatr 2014;168:664-70.

8 Wu S, Baker C, Lang ME, et al. Nebulized hypertonic saline for bronchiolitis: a randomized clinical trial. JAMA Pediatr 2014;168:657-63.

9 Teunissen J, Hochs AHJ, Vaessen-Verberne A, et al. The effect of $3 \%$ and $6 \%$ hypertonic saline in viral bronchiolitis: a randomised controlled trial. Eur Respir J 2014;44:913-21.

10 Everard ML, Hind D, Ugonna K, et al. SABRE: a multicentre randomised control trial of nebulised hypertonic saline in infants hospitalised with acute bronchiolitis. Thorax 2014:69:1105-12.

11 Royal College of Physicians. Why asthma still kills: the National Review of Asthma Deaths (NRAD) Confidential Enquiry report. London: RCP, 2014.

12 British Thoracic Society; Scottish Intercollegiate Guidelines Network. British guideline on the management of asthma. Thorax 2014;69(Suppl 1):1-192.

13 Bisgaard $\mathrm{H}$, Hermansen MN, Buchvald $\mathrm{F}$, et al. Childhood asthma after bacterial colonization of the airway in neonates. N Engl J Med 2007;357:1487-95.

14 Larsen JM, Brix S, Thysen AH, et al. Children with asthma by school age display aberrant immune responses to pathogenic airway bacteria as infants. J Allergy Clin Immunol 2014;133:1008-13.

15 Kloepfer KM, Lee WM, Pappas TE, et al. Detection of pathogenic bacteria during rhinovirus infection is associated with increased respiratory symptoms and asthma exacerbations. J Allergy Clin Immunol 2014;133:1301-7, 1307.e1-3.

16 Morton RW, Everard ML, Elphick HE. Adherence in childhood asthma: the elephant in the room. Arch Dis Child 2014;99:949-53.

17 Krishnan JA, Bender BG, Wamboldt FS, et al. Adherence to inhaled corticosteroids: an ancillary study of the Childhood Asthma Management Program clinical trial. J Allergy Clin Immunol 2012;129:112-18.

18 Stern L, Berman J, Lumry W, et al. Medication compliance and disease exacerbation in patients with asthma: a retrospective study of managed care data. Ann Allergy Asthma Immunol 2006:97:402-8.

19 Jentzsch NS, Camargos P, Sarinho ESC, et al. Adherence rate to beclomethasone dipropionate and the level of asthma control. Respir Med 2012;106:338-43.

20 Bender B, Zhang L. Negative affect, medication adherence, and asthma control in children. J Allergy Clin Immunol 2008;122:490-5.

21 Williams LK, Peterson EL, Wells K, et al. Quantifying the proportion of severe asthma exacerbations attributable to inhaled corticosteroid nonadherence. J Allergy Clin Immunol 2011;128:1185-91.e2.

22 Chan AHY, Reddel HK, Apter A, et al. Adherence monitoring and e-health: how clinicians and researchers can use technology to promote inhaler adherence for asthma. J Allergy Clin Immunol Pract 2013;1:446-54.

23 Vervloet M, Linn AJ, Van Weert JCM, et al. The effectiveness of interventions using electronic reminders to improve adherence to chronic medication: a systematic review of the literature. J Am Med Inform Assoc 2012;19:696-704.

24 Chan AHY, Stewart AW, Harrison J, et al. The effect of an electronic monitoring device with audiovisual reminder function on adherence to inhaled corticosteroids and school attendance in children with asthma: a randomised controlled trial. Lancet Respir Med 2015:3:210-19.

25 Robertson CF, Price D, Henry R, et al. Short-course montelukast for intermittent asthma in children: a randomized controlled trial. Am J Respir Crit Care Med 2007:175:323-9

26 Bacharier LB, Phillips BR, Zeiger RS, et al. Episodic use of an inhaled corticosteroid or leukotriene receptor antagonist in preschool children with moderate-to-severe intermittent wheezing. J Allergy Clin Immunol 2008;122:1127-35.e8.

27 Valovirta $\mathrm{E}$, Boza ML, Robertson CF, et al. Intermittent or daily montelukast versus placebo for episodic asthma in children. Ann Allergy Asthma Immunol 2011;106:518-26.

28 Nwokoro C, Pandya H, Turner S, et al. Intermittent montelukast in children aged 10 months to 5 years with wheeze (WAIT trial): a multicentre, randomised, placebo-controlled trial. Lancet Respir Med 2014;2:796-803. 
29 Roxburgh CSD, Youngson GG, Townend JA, et al. Trends in pneumonia and empyema in Scottish children in the past 25 years. Arch Dis Child 2008;93:316-18.

30 Koshy E, Murray J, Bottle A, et al. Impact of the seven-valent pneumococcal conjugate vaccination (PCV7) programme on childhood hospital admissions for bacterial pneumonia and empyema in England: national time-trends study, 1997-2008. Thorax 2010;65:770-4.

31 Bartlett JG. Diagnostic tests for agents of community-acquired pneumonia. Clin Infect Dis 2011;52(Suppl 4):S296-304.

32 Pernica JM, Moldovan I, Chan F, et al. Real-time polymerase chain reaction for microbiological diagnosis of parapneumonic effusions in Canadian children. Can J Infect Dis Med Microbiol 2014;25:151-4.

33 Nath S, Thomas M, Spencer D, et al. Has the incidence of empyema in Scottish children continued to increase beyond 2005? Arch Dis Child 2015;100:255-8.

34 Elemraid MA, Rushton SP, Shirley MDF, et al. Impact of the 7-valent pneumococcal conjugate vaccine on the incidence of childhood pneumonia. Epidemiol Infect 2013;141:1697-704.

35 Berglund $A$, Ekelund $M$, Fletcher MA, et al. All-cause pneumonia hospitalizations in children <2 years old in Sweden, 1998 to 2012: impact of pneumococcal conjugate vaccine introduction. PLOS ONE 2014;9:e112211.

36 Grijalva CG, Nuorti JP, Zhu Y, et al. Increasing incidence of empyema complicating childhood community-acquired pneumonia in the United States. Clin Infect Dis 2010;50:805-13.

37 Simonsen L, Taylor RJ, Young-Xu Y, et al. Impact of pneumococcal conjugate vaccination of infants on pneumonia and influenza hospitalization and mortality in all age groups in the United States. MBio 2011;2:e00309-10.

38 Miller E, Andrews NJ, Waight PA, et al. Herd immunity and serotype replacement 4 years after seven-valent pneumococcal conjugate vaccination in England and Wales: an observational cohort study. Lancet Infect Dis 2011;11:760-8.

39 Elemraid MA, Sails AD, Eltringham GJA, et al. Aetiology of paediatric pneumonia after the introduction of pneumococcal conjugate vaccine. Eur Respir $J$ 2013:42:1595-603

40 Slinger R, Hyde L, Moldovan I, et al. Direct Streptococcus pneumoniae real-time PCR serotyping from pediatric parapneumonic effusions. BMC Pediatr 2014;14:189.

41 Thomas MF, Sheppard CL, Guiver M, et al. Emergence of pneumococcal 19A empyema in UK children. Arch Dis Child 2012;97:1070-2.

42 Mckee AJ, Ives A, Balfour-Lynn IM. Increased incidence of bronchopulmonary fistulas complicating pediatric pneumonia. Pediatr Pulmonol 2011;46:717-21.

43 Rosen $\mathrm{CL}$, Larkin EK, Kirchner HL, et al. Prevalence and risk factors for sleep-disordered breathing in 8- to 11-year-old children: association with race and prematurity. J Pediatr 2003;142:383-9.
44 Marcus CL, Brooks LJ, Ward SD, et al. Diagnosis and management of childhood obstructive sleep apnea syndrome. Pediatrics 2012;130:e714-55.

45 Marcus $\mathrm{CL}$, Moore $\mathrm{RH}$, Rosen $\mathrm{CL}$, et al. A randomized trial of adenotonsillectomy for childhood sleep apnea. N Engl J Med 2013;368:2366-76.

46 Chervin RD, Ellenberg SS, Hou X, et al. Prognosis for spontaneous resolution of obstructive sleep apnea in children. Chest 2015 Mar 26. doi:10.1378/chest.142873 [Epub ahead of print]

47 Konstantinopoulou S, Gallagher P, Elden L, et al. Complications of adenotonsillectomy for obstructive sleep apnea in school-aged children. Int I Pediatr Otorhinolaryngol 2015;79:240-5.

48 Lucas IS, Burgess A, Mitchison HM, et al. Diagnosis and management of primary ciliary dyskinesia. Arch Dis Child 2014;99:850-6.

49 Knowles MR, Daniels LA, Davis SD, et al. Primary ciliary dyskinesia. Recent advances in diagnostics, genetics, and characterization of clinical disease. Am J Respir Crit Care Med 2013;188:913-22.

50 Kennedy MP, Omran H, Leigh MW, et al. Congenital heart disease and other heterotaxic defects in a large cohort of patients with primary ciliary dyskinesia. Circulation 2007;115:2814-21.

51 Horani A, Brody SL, Ferkol TW. Picking up speed: advances in the genetics of primary ciliary dyskinesia. Pediatr Res 2014;75:158-64.

52 Knowles MR, Ostrowski LE, Leigh MW, et al. Mutations in RSPH1 cause primary ciliary dyskinesia with a unique clinical and ciliary phenotype. Am J Respir Crit Care Med 2014;189:707-17.

53 Davis SD, Ferkol TW, Rosenfeld M, et al. Clinical features of childhood primary ciliary dyskinesia by genotype and ultrastructural phenotype. Am I Respir Crit Care Med 2015;191:316-24.

54 Kurland G, Deterding RR, Hagood JS, et al. An official American Thoracic Society clinical practice guideline: classification, evaluation, and management of childhood interstitial lung disease in infancy. Am J Respir Crit Care Med 2013;188:376-94.

55 Fan LL, Deterding RR, Langston C. Pediatric interstitial lung disease revisited. Pediatr Pulmonol 2004;38:369-78.

56 Deutsch GH, Young LR, Deterding RR, et al. Diffuse lung disease in young children: application of a novel classification scheme. Am J Respir Crit Care Med 2007:176:1120-8.

57 Wambach JA, Casey AM, Fishman MP, et al. Genotype-phenotype correlations for infants and children with ABCA3 deficiency. Am J Respir Crit Care Med 2014;189:1538-43.

58 Bush $A$, Anthony $G$, Barbato $A$, et al. Research in progress: put the orphanage out of business. Thorax 2013;68:971-3. 